7. Child Lang. 36 (2009), 673-684. (C) 2008 Cambridge University Press doi:I0.1017/So30500090800902 I Printed in the United Kingdom

B R I E F RESEARCH REPOR T

\title{
Preschoolers' word mapping: The interplay between labelling context and specificity of speaker information*
}

\author{
ELIZABETH S. NILSEN \\ University of Waterloo \\ SUSAN A. GRAHAM \\ University of Calgary \\ AND \\ TAMARA PETTIGREW \\ Concordia University
}

(Received 5 March 2008. Revised I6 May 2008. First published online I7 October 2008)

\section{ABSTRACT}

We assessed the effect of specificity of speaker information about an object on three-year-olds' word mappings. When children heard a novel label followed by specific information about an object at exposure, children subsequently mapped the label to that object at test. When children heard only specific information about an object at exposure, they inferred that the label applied to a different object at test. Finally, non-specific information did not assist children in mapping a word to an object. Thus, children use speaker information as a word-mapping cue but this information is interpreted differently depending on how the discourse is initiated.

Young children are highly successful at resolving the apparent ambiguity inherent in word learning. That is, young word learners can recruit

[*] This research was supported by an operating grant from the Social Sciences and Humanities Research Council of Canada and funding from the Canada Research Chairs program awarded to SG. TP was supported by a summer studentship from AHFMR. We thank the parents and children who participated in the studies, and Carlene Adamache for her assistance with this research. Data from these experiments were presented at the International Conference on Infant Studies, Brighton, UK. Address for correspondence: Susan Graham, Dept. of Psychology, University of Calgary, Calgary, AB T2N I $\mathrm{T}_{4}$ Canada. e-mail: susan.graham@ucalgary.ca 
information from a variety of sources when faced with the task of identifying an intended referent from an array of potential referents (see Baldwin \& Meyer, 2007; Diesendruck, 2007, Hall \& Waxman, 2004; Waxman \& Lidz, 2006, for recent reviews). One particular source of guidance that young children can exploit in a word learning task is their sensitivity to others' referential intentions (e.g. Akhtar \& Tomasello, 2000). In the present study, we examined preschoolers' tendency to monitor an adult's referential intent to access word meaning, with specific focus on whether the specificity of information provided by a speaker about an object influenced their mappings of new words to novel objects.

A number of studies have demonstrated that even very young word learners actively seek out and use cues to the intentional state of speakers, such as monitoring their eye gaze, facial expressions and behaviours, to map novel words to objects or actions (e.g. Akhtar \& Tomasello, r 996; Baldwin, I $993 a$, I993 $b$; Diesendruck, Markson, Akhtar \& Reudor, 2004). For example, Baldwin demonstrated that infants at $1 ; 6$ followed a speaker's direction of gaze to map a novel word to a referent object, even if the object the speaker was looking at was out of the infants' view when the novel label was provided (Baldwin, I 99 I, I 993 $a$ ). Similarly, Tomasello and colleagues found that infants at $1 ; 6$ and 2;0 mapped words based on a speaker's non-linguistic expression of success versus disappointment (Tomasello \& Barton, I994; Tomasello, Strosberg \& Akhtar, I 996). Finally, infants mapped words to actions that were deemed to be intentional (e.g. researcher said 'there!' following action) rather than those viewed as accidental (e.g. researcher said 'whoops!' following action; Tomasello \& Barton, I 994). Together, these studies suggest that young children are able to draw on numerous cues that provide a window into the adult's intended reference to guide their word mapping.

In addition to following behavioural and linguistic cues from the speaker, young word learners come to infer the intentions of a speaker through actively monitoring the discourse situation. That is, young children will rely on the relative novelty within the discourse context to successfully map words to referents (Akhtar, Carpenter \& Tomasello, I 996; Akhtar \& Tomasello, I996). For example, two-year-old children were more likely to map novel labels to objects that are unfamiliar to the speaker (but not unfamiliar to the child) than to those objects with which the speaker had previously interacted (Akhtar et al., I996; Diesendruck et al., 2004). Similarly, children can monitor the discourse context to determine whether a novel word refers to an action versus an object (Tomasello \& Akhtar, I 995). Finally, research by Clark and her colleagues have demonstrated that young children mine conversational exchanges for hypotheses about novel word meanings (Clark \& Wong, 2002). For example, Clark (2007) demonstrated that young children regularly uptake new words in conversations 
and begin to assign meaning based on that context. Moreover, through regularities in the way that adults provide direct offers of new terms when conversing (Clark \& Wong, 2002), children develop expectations for the way in which new words are introduced and respond in particular ways when a new word is detected (Clark, 2007).

In the present study, we pursued the investigation of three-year-olds' use of an adult speaker's information to disambiguate the referent of a novel word when faced with more than one novel (i.e. nameless) object. Our study focused on three specific issues. First, we examined whether the way in which an interaction was initiated influenced how preschoolers interpreted a speaker's subsequent information of a nameless object. Specifically, we examined whether hearing a clear statement of intent introducing a novel word (e.g. 'Let's find a $f e p$ ') versus a more general intentional statement (e.g. 'Are you ready to look at some things?') prior to attention to one of two nameless objects affected how children inferred the speaker's intentions from her subsequent behaviour. Second, we investigated whether the specificity of information, that is, amount of disambiguating detail, provided by a speaker influenced preschoolers' tendency to map a novel word to a particular object. While many studies have examined the importance of basic pragmatic conditions for word learning (e.g. sharing a joint focus of attention, or using a physical co-presence to arrive at a correct referent for a novel label; e.g. Baldwin I99I; Carpenter, Nagell \& Tomasello, I998), no research has examined the nature of the shared attention with respect to the degree to which it includes information that disambiguates between referents. In our study, we examined whether the specificity of the interaction with a particular object influenced children's tendency to map a novel word to that object. Finally, we examined how these two factors might interact. That is, we examined whether the same type of information led to differential wordmapping performance depending on whether or not the experimenter began the interaction with a clear statement of intent. This final research focus, investigating how a speaker cue may be interpreted differentially depending on the context, is particularly important given that everyday word learning occurs against a rich contextual backdrop. While research on children's word learning has provided invaluable insight into how children acquire words, there has been significantly less attention to how their word learning proceeds in contexts with multiple inputs (Saylor, Baldwin \& Sabbagh, 2004).

In this study, three-year-olds were presented with pairs of unfamiliar objects over a series of trials. At the beginning of each trial, preschoolers were told that the researcher wanted to find either the referent of a novel word (e.g. 'Let's find a $f e p$ ') or 'look at some things' prior to the introduction of the speaker information manipulation. Following that introduction, the researcher interacted with one of the objects in the pair (i.e. the target object) in a particular fashion that varied in degree of 
specificity - she either generally attended to the object (e.g. 'See this one, look at this one.'), provided non-specific information about the object (e.g. 'See this one, it's on the table.') or provided information that was specific to that object (e.g. 'See this one, you can squeeze this one.'). Both objects were then placed on a tray and children were asked for the referent object of a new word (e.g. 'Show me a fep.'). Thus, when the experimenter directed general attention to the object or described non-specific information about it, the target object (i.e. the recipient of the speaker attention) was not identified with any unique information; it was simply the focus of the speaker's attention. In contrast, when the experimenter provided specific information about the target object, the target object was identified with unique information that applied only to this object.

Our predictions and the rationale for these predictions were as follows. First, we expected that preschoolers would be more likely to interpret the speaker's behaviour as evidence of referential intent when she had clearly signalled that she was searching for the referent of a novel word versus when she had simply indicated that she and the child were going to look at some objects. That is, we predicted that when children hear a speaker announce that she wants to find the referent of a novel word, they would expect that the next piece of information provided in the interaction would fit with those intentions and disambiguate the referent of that novel word. Second, we predicted that preschoolers would be sensitive to the type of speaker information when faced with the task of inferring the speaker's intentions, as reflected in differential word-mapping performance across groups. Specifically, we predicted that preschoolers would ignore general information that fails to disambiguate between the two objects, but would infer that a novel label referred to a novel object if specific information was provided about the target object. On the other hand, if preschoolers interpret any type of attention to a nameless object as evidence of referential intent, then we expected that they would be as likely to map the novel word to the target object when the experimenter provided general attention, nonspecific information or specific information about the object. As per the first prediction, however, we anticipated children's sensitivity to and use of quality of speaker attention would be influenced by the manner through which the speaker voiced her initial intentions. That is, they may be more willing to accept non-specific attention as an indication of intention if the speaker introduced the discourse with a clear signal of her purpose.

\section{METHOD}

\section{Participants}

The final sample consisted of 126 three-year-old children, ranging in age from 3 ; o to 3 ; 9 . Children were recruited from local preschools, childcare 
PRESCHOOLERS' WORD MAPPING

TABLE I. Mean ages and gender distribution by group

\begin{tabular}{|c|c|c|c|c|c|}
\hline $\begin{array}{l}\text { Introduction } \\
\text { Type }\end{array}$ & Description type & $\mathrm{n}$ & $\begin{array}{l}\text { Mean } \\
\text { age }\end{array}$ & $\begin{array}{l}\text { Age } \\
\text { range }\end{array}$ & Gender \\
\hline \multirow[t]{3}{*}{ No Label } & General Attention & $2 I$ & $3 ; 4$ & $3 ; \circ-3 ; 9$ & \multirow{3}{*}{$\begin{array}{l}\text { I I boys, I o girls } \\
\text { I o boys, I I girls } \\
\text { ro boys, I I girls }\end{array}$} \\
\hline & Non-specific Description & $2 \mathrm{I}$ & $3 ; 5$ & $3 ; \mathrm{I}-3 ; 9$ & \\
\hline & Specific Description & $2 \mathrm{I}$ & $3 ; 6$ & $3 ; 2-3 ; 9$ & \\
\hline \multirow[t]{3}{*}{ Novel Label } & General Attention & $2 \mathrm{I}$ & $3 ; 5$ & $3 ; \circ-3 ; 9$ & \multirow{3}{*}{$\begin{array}{l}\text { I o boys, I I girls } \\
\text { I I boys, r o girls } \\
\text { I o boys, I I girls }\end{array}$} \\
\hline & Non-specific Description & $2 \mathrm{I}$ & $3 ; 4$ & $3 ; \circ-3 ; 9$ & \\
\hline & Specific Description & $2 \mathrm{I}$ & $3 ; 5$ & $3 ; 0-3 ; 9$ & \\
\hline
\end{tabular}

centres and from community health clinics. Children were randomly assigned to one of six groups that varied in introduction type and description type. See Table I for mean ages and gender distribution in the six groups. Five additional children were tested but excluded from the final sample for reasons including providing a label for an unfamiliar object (3) and failure to complete the practice trials (2).

\section{Materials}

Eight familiar toy objects were used in the practice trials: a cup, a spoon, a chair, a car, a stuffed frog, a stuffed monkey, a bowl and a baby shoe. Four sets of two different household objects were used as unfamiliar objects for the test trials: a garlic press and honey dipper, a corkscrew and bottle top, a sink plunger and turkey baster, and an apple corer and clothesline pulley. To ensure that children in this age range did not have labels for these objects, we conducted a pretest with five-year-olds (six males and four females, $M=5 ; 2, S D=9$ months). We presented children with each object and asked them to label the object. At least eight of the ten children were unable to generate a label for each of the objects used in this experiment, indicating that these objects are unfamiliar to five-year-olds, and thus unfamiliar to three-year-olds. The descriptors used to describe objects in the Specific Description groups were as follows: turkey baster - 'squeeze it'; honey dipper - 'tap it'; corkscrew - 'spin it'; bottle top - 'turn it'; apple corer - 'twirl it'; and clothesline pulley - ' roll it'. The labels used to request objects were: fep, wug, blick and dax.

\section{Procedure}

Children were tested individually and were seated at a table across from the experimenter. Children first were introduced to a puppet ('Doggy') and given a practice task in which they were presented with two familiar objects and were asked to choose the referent of one of a familiar label (e.g. shown a cup and a spoon, and were asked: 'Can you show Doggy a cup?'). This 
procedure was repeated for a total of four practice trials. The practice task allowed children to become comfortable with choosing objects on the left and right sides, and familiarized them with the procedure. All children included in the study successfully completed the practice task.

Following the practice trials, children were exposed to the first pair of unfamiliar objects for 40 seconds (e.g. turkey baster and sink plunger). Children were allowed to touch and explore the objects during this time. Next, the experimenter put the objects back on the tray and the procedure then diverged according to the group to which the child had been assigned. In the three Novel Label Introduction groups, the experimenter first announced her intention to find a particular object (e.g. 'Let's find a fep.') while looking at the child's face. In contrast, in the three No LABEL INTRODUCTION conditions, the experimenter merely said, 'Are you ready to look at some things now?' 'The experimenter then interacted with one of the objects, while the second object remained in view. The type of interaction varied according to group. In the General Attention groups, the experimenter picked up one of the objects, looked at it, and said, 'See this one, look at this one.' She then handed the object to the child and said, 'Here, you can look'. In the Non-SPECIFIC Description groups, the experimenter pointed to one of the objects, looked at it, and described an uninformative fact about the object. That is, when focusing attention on one of the objects, the experimenter showed the child the object and said, 'See this one, it's on the table'. She then picked up the object and handed it to the child and said, 'Here, you can look'. In the Specific Description groups, the experimenter described a specific property of the object. That is, when focusing attention on one of the objects, the experimenter picked up the object (e.g. turkey baster) and said, 'See this one, you can squeeze this one'. She then handed the object to the child and said, 'Here, you can try'. In all groups, the experimenter did not direct any attention toward the other object in the pair, and if a child asked about the other object, the experimenter would redirect the child's attention to the object that was the target of the attention. Across all three groups, the duration of the speaker's attention to the target object was similar.

Following this exposure, the procedure converged again in all groups. The two objects were placed back on the tray and children were asked for the referent of a new word using the puppet (e.g. Puppet says 'I want a fep. Show me a fep', followed by 'Can you show Doggy a fep?'). This label was the same as that used by the experimenter in the Novel Label Introduction conditions. Once the child chose an object the experimenter recorded the child's choice and proceeded to the next trial. This procedure was repeated for the remaining three trials. The order of pairs of objects, their location on the tray (i.e. left or right side) and the object that was the target of the experimenter's attention was counterbalanced across trials and participants. 


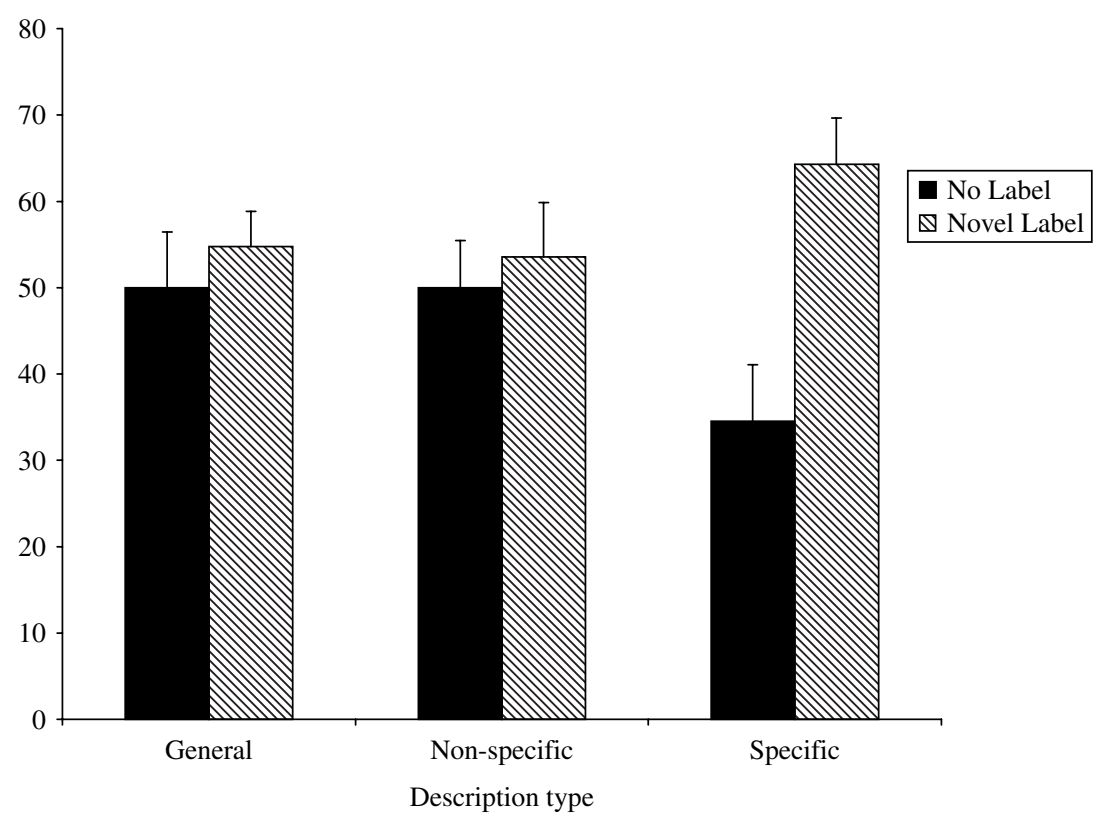

Fig. I. Mean percentage of target object choices by introduction and description type.

\section{RESULTS}

The questions of interest were whether the introduction type and subsequent description of a novel object influenced preschoolers' tendency to select that novel object as the referent of a novel word. To assess these questions, we first computed the percentage of target object choices across trials. The means are presented in Figure I. To examine possible group differences on performance on the word-mapping trials, we performed a 2 (Introduction Type: Novel Label vs. No Label) $\times 3$ (Description Type: General, Non-specific, Specific) analysis of variance (ANOVA) on these data. This analysis yielded a significant main effects of introduction type $\left(F(\mathrm{I}, \mathrm{I} 20)=7 \cdot 28, \quad \eta^{2}=0.06, \quad p=0.008\right)$ and a significant interaction of introduction type by description type $\left(F(2,120)=3.29, \eta^{2}=0.05, p=0.04\right)$. To understand the source of this interaction, we compared the effects of introduction type for each description type separately using independent groups $t$-tests with a Bonferroni correction $(p=0 \cdot 0 \mathrm{r} 6)$. When the experimenter either described the target objects with a general attentional phrase or with a non-specific description, word-mapping performance in the No Label and the Novel Label introduction groups did not differ $\left(p_{\mathrm{s}}>0.50\right)$. In contrast, when the experimenter provided a specific description of the object, children in the Novel Label group were significantly more likely to 
TAB LE 2. Number of consistent choosers by group

\begin{tabular}{llc}
\hline $\begin{array}{l}\text { Introduction } \\
\text { type }\end{array}$ & \multicolumn{1}{c}{ Description type } & $\begin{array}{c}\text { Number of } \\
\text { consistent choosers }\end{array}$ \\
\hline No Label & General Attention & 6 \\
& Non-specific Description & 8 \\
& Specific Description & $5^{\mathrm{a}}$ \\
Novel Label & General Attention & 8 \\
& Non-specific Description & 6 \\
& Specific Description & I $^{\mathrm{b}}$ \\
\hline
\end{tabular}

a Significantly less than chance, $p<0.05$.

${ }^{\mathrm{b}}$ Significantly greater than chance, $p<0.05$.

map the novel word onto the target object than children in the No Label group $(t(40)=3.52, p=0.00 \mathrm{I})$. These findings indicate that only providing a specific description of a target object, following the introduction of a novel label, led children to map novel labels to these target objects.

We then compared the mean percentage of target object choices to chance levels $(50 \%)$ for each group, using one-sample $t$-tests. Only children in the Specific Description groups selected the target object at level that differed from chance. That is, children in the Novel Label Introduction-Specific Description group chose the target object on the word-mapping trials significantly more often than would be expected by chance $(t(20)=2 \cdot 67$, $p=0.02)$. In contrast, children in the No Label Introduction-Specific Description group chose the target object on the word-mapping trials significantly less often than would be expected by chance $(t(20)=2 \cdot 36$, $p=0.03)$. Thus, when a speaker voiced her intention to find an object using a novel label, preschoolers mapped this label onto the object that had been described with specific information. In contrast, when no novel label was provided initially, children chose the object that was not attended to as the referent for the novel term.

Finally, we examined individual children's consistency in choosing the target object across trials in each group. We classified any child who made three or four out of four target object choices a Consistent Chooser and, using the binomial theorem, determined that the probability classification as a Consistent Chooser was 0.3 I 25 (see Table 2). We then used the binomial theorem again to calculate whether the number of Consistent Choosers in each group was greater than what would be expected by chance alone. Consistent with the above analyses, there were significantly more Consistent Choosers in the Novel Label Introduction-Specific Description group $(N=\mathrm{II})$ than would be expected by chance $(p=0.02)$. In contrast, the number of children in the No Label Introduction-Specific Description group that were classified as Consistent Choosers was less than that 
expected by chance $(N=5 ; p=0.03)$. In the other groups, however, the numbers of Consistent Choosers were no different than what would be expected by chance.

\section{DISCUSSION}

Our findings demonstrate that the nature of the interaction initiation interacted with the speaker's information to guide preschoolers' novel object word mappings. Children were more likely to map the novel label to the intended target when, at exposure, they heard the speaker first provide the label and then provide specific information that allowed the child to identify the intended referent. In contrast, when children did not hear the label at exposure but were provided with specific information from the speaker, at test, they inferred that the label must apply to something else, namely the second object in the task. Finally, when the speaker's interaction with the object did not provide specific information about the target object, regardless of the whether the label was provided at exposure or not, children were as likely to map the novel word to that object as they were to map the word to the second object in the pair. Thus, preschoolers did not consider simply interacting with an object to be an indication of referential intent.

Our findings offer a number of insights into young word learners' attention to pragmatic information. First, our results demonstrate that hearing a novel word at the outset of an interaction prompts preschoolers to monitor the subsequent interaction for information about the possible meaning of that novel word. When preschoolers do not have that impetus, they interpret the interaction in very different ways. When asked for the referent of a novel word, children do not interpret a speaker's previous interaction with an object as evidence of referential intent. That is, in our study, preschoolers did not reason that a novel label mapped to an object that the experimenter had previously interacted with, if they had not experienced the novel label before that interaction occurred. Whereas previous work has demonstrated that children will monitor and use cues from a speaker to guide their word mapping (e.g. Akhtar \& Tomasello, I996; Baldwin I99I), the present work demonstrates that children's interpretation of the meaning of a particular speaker cue depends on how the interaction was initiated. That is, the same cue, in this case, specific information about an object, is interpreted as referential intent ONLY when the interaction is initiated with a novel label.

Second, the results demonstrate that preschoolers are sensitive to the degree of specificity of information provided by the speaker when they monitor the interaction to infer the intentions of speakers. When the speaker set up the interaction using a novel label, children interpreted distinguishing information about an object, but not general attention to it, 
as evidence that this object was the referent of the novel word. When disambiguating information for a novel word was not provided (as with the general and non-specific attention groups), children did not see the attention by the speaker as being linked to the new term. This suggests that when children hear a speaker announce that she wants to find the referent of a novel word, they expect that the next piece of information provided in the interaction will disambiguate the referent of that novel word. When disambiguating information is not provided, they do not reason that the attention is related to the novel word previously uttered by the speaker. These results are consistent with findings that young children are sensitive to the discourse situation when learning new words (Clark, 2007). Moreover, considering that the manner through which adults offer new terms to children often follows a specific form (Clark \& Wong, 2002), our results suggest that children may come to expect a certain type of information after a new word as been presented.

Children's sensitivity to the nature of speaker information may be representative of an emergent appreciation for conversational pragmatics. That is, in everyday conversation, speakers generally provide as much information as required for referent identification and listeners expect unambiguous, but concise, descriptions (Grice, I975). Sensitivity to adults' tendency to adhere to this conversational principle may be guiding children's performance in our study in the following way: when the speaker provides uninformative cues about an object, children's expectations about the specificity of the information leads them to disregard general information that does not meet these expectations.

Finally, our findings offer support for the notion that preschoolers have the tendency to avoid overlap in communicative interactions. Recall that when the speaker set up the exchange in a general manner, children interpreted specific information about an object as an indication that the novel label applied to the other nameless object. In this situation, then, it appears that children made the pragmatic inference that, if a speaker uses two referential forms, it is likely because he or she has two different intents in mind (Clark, I987, I990). For example, upon hearing a speaker describe an object saying 'you can squeeze this one' and then ask for the referent of a novel word, preschoolers must have assumed that the speaker would not intend to use a second referential form to refer to an object previously referred to with a different referential form, given that there are two nameless objects in the context. Thus, they infer that the speaker must intend to refer to the second nameless object with the novel word and consequently map the label to that object.

Our finding that children sought to avoid overlap in referential forms is consistent with other recent studies using a variety of different referential forms. For example, Diesendruck \& Markson (200I) demonstrated that 
children avoided linking either two count nouns or two facts used referentially to a single object. That is, when shown two novel objects, taught a fact about one of them (e.g. 'My uncle gave me this one.'), and then asked for the referent of a different fact (e.g. 'Show me the one from Mexico.'), children tended to select the object that did not receive a fact previously. In a similar vein, Diesendruck (2005) found that preschoolers avoided overlap between the two referential forms, even if they differed in form class (i.e. a proper name and a count noun). Finally, Diesendruck, Hall \& Graham (2006) demonstrated that four-year-olds made a contrastive pragmatic inference regarding the referents of two different prenominal adjectives.

In summary, the results of the present study offer insight into the manner through which children process the pragmatic information in word learning situations. Specifically, our findings demonstrate that when inferring referential intent, children interpret the information provided by the speaker within the context of that speaker's initial statements.

\section{REFERENCES}

Akhtar, N., Carpenter, M. \& Tomasello, M. (1996). The role of discourse novelty in early word learning. Child Development 67, 635-45.

Akhtar, N. \& Tomasello, M. (I996). Two-year-olds learn words for absent objects and actions. British Fournal of Developmental Psychology 14, 79-93.

Akhtar, N. \& Tomasello, M. (2000). The social nature of words and word learning. In M. Marschark (series ed.), Counterpoints: Cognition, memory, and language. Becoming a word learner: A debate on lexical acquisition, II 5-35. New York: Oxford University Press.

Baldwin, D. A. (1991). Infants' contribution to the achievement of joint reference. Child Development 62, 875-90.

Baldwin, D. A. (I993a). Infants' ability to consult the speaker for clues to word reference. Fournal of Child Language 2o, 395-4i 8.

Baldwin, D. A. (1993b). Early referential understanding: Infants' ability to understand referential acts for what they are. Developmental Psychology 29, 832-43.

Baldwin, D. A. \& Meyer, M. (2007). How inherently social is language? In E. Hoff \& M. Shatz (eds), Blackwell handbook of language development, 87-106. Malden, MA: Blackwell Publishing.

Carpenter, M., Nagell, K. \& Tomasello, M. (I 998). Social cognition, joint attention, and communicative competence from 9 to 15 months of age. Monographs of the Society for Research in Child Development 63(4) (Serial No. 255).

Clark, E. (1987). The principle of contrast: A constraint on language acquisition. In B. MacWhinney (ed.), Mechanisms of language acquisition, I-33. Hillsdale, NJ: Lawrence Erlbaum Associates.

Clark, E. (I990). On the pragmatics of contrast. Fournal of Child Language I7, 4I 7-3 I.

Clark, E. (2007). Young children's uptake of new words in conversation. Language in Society 36, I $57-82$.

Clark, E. \& Wong, A. (2002). Pragmatic directions about language use: Offers of words and relations. Language in Society 31, I 8 I-2 I 2.

Diesendruck, G. (2005). The principles of conventionality and contrast in word learning: An empirical examination. Developmental Psychology 4I, 45 I-63.

Diesendruck, G. (2007). Mechanisms of word learning. In E. Hoff \& M. Shantz (eds), Blackwell handbook of language development, 257-76. Malden, MA: Blackwell Publishing. 
Diesendruck, G., Hall, D. G. \& Graham, S. A. (2006). Children's use of syntactic and pragmatic knowledge in the interpretation of novel adjectives. Child Development 77, I6-30.

Diesendruck, G. \& Markson, L. (200I). Children's avoidance of lexical overlap : A pragmatic account. Developmental Psychology 37, 630-4I.

Diesendruck, G., Markson, L., Akhtar, N. \& Reudor, A. (2004). Two-year-olds' sensitivity to speakers' intent: An alternative account of Samuelson and Smith. Developmental Science 7, 33-4I.

Grice, P. (I975). Logic and conversation. In P. Cole \& J. Morgan (eds), Syntax and semantics 3: Speech acts, 4I-58. New York: Academic Press.

Hall, D. G. \& Waxman, S. R. (eds) (2004). Weaving a lexicon. Cambridge, MA: MIT Press.

Saylor, M. M., Baldwin, D. A. \& Sabbagh, M. A. (2004). Converging on word meaning. In D. G. Hall \& S. R. Waxman (eds), Weaving a lexicon, 509-568. Cambridge, MA: MIT Press.

Tomasello, M. \& Akhtar, N. (I995). Two-year-olds use pragmatic cues to differentiate reference to objects and actions. Cognitive Development 1o, $20 \mathrm{I}-224$.

Tomasello, M. \& Barton, M. (I 994). Learning words in non-ostensive contexts. Developmental Psychology 3o, 639-50.

Tomasello, M., Strosberg, R. \& Akhtar, N. (1996). Eighteen-month-old children learn words in non-ostensive contexts. Fournal of Child Language 23, I 57-76.

Waxman, S. \& Lidz, J. (2006). Early word learning. In D. Kuhn, R. Siegler, W. Damon \& R. Lerner (eds). Handbook of child psychology: Vol. 2, Cognition, perception, and language, 6th ed., 299-335. Hoboken, NJ : John Wiley \& Sons, Inc. 